\title{
Direct Liquefaction Characteristics of Spirulina, Spartina alterniflora and Soy Protein in the Ethanol-Water Co-solvent System for Bio-oil Production
}

\author{
Osman Hifni ${ }^{1}$, Bo Zhang ${ }^{2,3}$, Zhixia $\mathrm{He}^{1,2^{*}}$, Huan Feng ${ }^{1}$, Guisheng $\mathrm{Xu}^{1}$ \\ ${ }^{1}$ School of Energy and Power Engineering, Jiangsu University, Zhenjiang 212013, China \\ ${ }^{2}$ Institute for Energy Research, Jiangsu University, Zhenjiang 212013, China \\ ${ }^{3}$ Key Laboratory of Low-grade Energy Utilization Technologies and Systems (Chongqing University), Ministry of Education of China, Chongqing \\ University, Chongqing 400044, PR China
}

DOI: $10.36348 /$ sjet.2019.v04i12.004

| Received: 14.12.2019 | Accepted: 23.12.2019 | Published: 28.12.2019

*Corresponding author: Zhixia He

\section{Abstract}

In the scope of this research, the direct liquefaction (DL) of microalgae (Spirulina, Spartina alterniflora) and soy protein was performed in a co-solvent system consisted of water and ethanol (EWCS). We investigated the effect of reaction time, reaction temperature, an alkaline catalyst $\left(\mathrm{Na}_{2} \mathrm{CO}_{3}\right)$, and the Ethanol-Water Co-Solvent system on the liquefaction yields and bio-oil properties. The outcome of the experiments elucidated a bio-oil yield of $49.4 \%, 50.2 \%$ and $42.7 \%$ for Spirulina, Spartina alterniflora and Soy protein respectively in which it is much higher than the HTL runs with pure water indicating the positive effect of co-solvent on the liquefaction, and for catalytic runs the bio-oil yields were $53.7 \%$, $50.2 \%$, and $31.6 \%$ respectively. When compared to non-catalytic DL, $\mathrm{Na}_{2} \mathrm{CO}_{3}$ relatively increased the bio-oil yield of the algae samples and decreased it for the Soy protein samples. The GC-MS and FT-IR analyses displayed that there are some differences in the chemical composition and the content of compounds among the bio-oils, where the significant components were esters, ketones, amides, acids, and nitrogen-containing heterocycles. Apart from its influence on the product yield, the usage of $\mathrm{Na}_{2} \mathrm{CO}_{3}$ showed no significant impact on the properties of the bio-oil.

Keywords: Direct liquefaction; Microalgae; $\mathrm{Na}_{2} \mathrm{CO}_{3}$; Co-solvent; Bio-oil; Soy protein.

Copyright @ 2019: This is an open-access article distributed under the terms of the Creative Commons Attribution license which permits unrestricted use, distribution, and reproduction in any medium for non-commercial use (NonCommercial, or CC-BY-NC) provided the original author and source are credited.

\section{INTRODUCTION}

Since humankind evaluation had and shall always depend on energy resources, obtaining a sustainable and affordable energy source is still a priority yet. The hunt for new energy resources has been drafting back since the discovery of fossil fuels in the eighteen's century leading to the greatest industrial revolution ever and becoming the most critical and dominate energy source. As a result, holding back the quest for new energy sources until the following group of serious issues popped up to the surface, such as the excessive and unstrained consumption of fossil fuels leading to the deteriorative atmospheric greenhouse effect, air pollution, and global warming. Since over 11 billion tons of oil is consumed every year, concerning the fact that fossil fuels are finite, and it will eventually run out [1]. Crude oil reserves are vanishing at the rate of 4 billion tons a year [2] and if carrying on at this rate, the known oil deposits will only last until 2052. With these problems, the quest for new energy resources is back in track, gaining a great deal of attention in the past decades.

Bio-fuels, which is driven from biomass, is representing a promising alternative for fossil fuels. Biomass is a renewable and carbon-neutral source because all the carbon in biomass comes from the atmosphere while the plants are growing and then shall be rereleased to the atmosphere when it is burned. Biomass now is the fourth most abundant energy source in the world [3]. Biofuels can be classified according to their differences in raw materials that are the first, second and third generation categories [4]. Generally, the first- and second-generation biofuels can be produced from the seeds of plants like soybean, rape (canola) and sunflower and non-food crops like rape straw, respectively [5].

Comparing with the first- and secondgeneration biofuels, the third-generation biofuel which is come from microalgae are generally less expensive 
than food crops and also ameliorate concerns over competition with food supplies [6]. To convert microalgae biomass into liquid biofuels, fast pyrolysis and direct liquefaction (DL) represent the two main thermochemical conversions methods [7]. Generally, in the fast pyrolysis process, the feedstock should be prior heated up slowly over hours to days to lower its moisture content because the fast pyrolysis is a dry-base feedstock process with moisture content below $10 \%$ [8]. Microalgae contain approximately $80-90 \%$ moisture is unsuitable to use fast pyrolysis to obtain biofuels because it would consume a great deal of energy following the pre-processing.

On the other hand, DL process is a promising candidate to deal with such wet biomass, and it has lower reaction temperature and higher energy efficiency than that of fast pyrolysis process because the energyintensive pre-drying steps are not required [9]. Liquefaction, also termed as thermochemical liquefaction or hydrothermal liquefaction (HTL), is a thermal process to convert wet microalgal biomass into liquid fuel where hot compressed or sub-critical water is employed. In general, the liquefaction is operated at temperatures of $300-350{ }^{\circ} \mathrm{C}$ and pressures of 5-20 $\mathrm{MPa}$ [10]. Water is the most widely used liquefaction solvent. Although water at sub-critical conditions becomes a useful solvent and it is less corrosive than other chemical solutions, it is accompanied with many shortcomings such as water reached up to the critical value $\left(374.3{ }^{0} \mathrm{C}, 22.1 \mathrm{MPa}\right)$ need higher energy consumption due to the large specific heat [11]. The bio-oil which is obtained from liquefaction of biomass contains a high amount of nitrogen and oxygen, and this limits its application [12, 13].To enhance the bio-oil yield with lower oxygen content, organic solvents, such as ethanol, methanol, and acetone, have been utilised as the reaction medium instead of water [14-17]. The presence of organic solvents, whose critical points are much lower than that of water, could succeed in converting biomass into bio-oils under milder reaction conditions.

As one of the universal alcohols applied in industry, ethanol is considered to be the most suitable solvent for the liquefaction of algal biomass [18]. Ethanol has relatively lower critical value $\left(240.8^{0} \mathrm{C}\right.$, $6.14 \mathrm{MPa})$, higher reported bio-oil yield (53.4\%) and conversion rate $(86.3 \%)$ [19] and it is also a renewable resource and a green reagent. Beside the non-catalytic
DL, there was an introduction for different types of catalysts in the DL process that has been reported [2025]. The common purpose of using the catalyst is to maximise the bio-oil yield and improve its quality. Most of the studies have used $\mathrm{Na}_{2} \mathrm{CO}_{3}$ as a homogenous catalyst during HTL. However, some studies [21, 26] concluded that the bio-oil yield decreased while some studies [20, 24] indicated an increase in the bio-oil yield with the use of $\mathrm{Na}_{2} \mathrm{CO}_{3}$. Thus, there is a lack of understanding of the effect of $\mathrm{Na}_{2} \mathrm{CO}_{3}$ on the bio-oil yield and its quality obtained from algae strains.

Microalgae mainly consist of proteins, carbohydrates, and lipids, but also containing some pigments, inorganic compounds, and even nucleic acids. This complex formation makes it relatively hard to keep up and fully understand the reaction pathways that take place during HTL. So to overcome this shortage, a model system was suggested in which it can provide more explicit information than that of the actual algal biomass. Following the three major components of microalgae, protein plays a crucial role in determine the oil quality since its fraction contains all three major heteroatoms ( $\mathrm{N}, \mathrm{S}$, and $\mathrm{O})$. So, the protein was chosen to be tested in the HTL process in our research hoping that it can provide a broader and more detailed vision about the catalytic HTL process of microalgae. In the present study, soy protein was chosen because of its similar characteristics to the protein present in many microalgae species [26] as well as being commercially available.

\section{MATERIALS AND METHODOLOGY Materials}

All samples in a powder form were Biotechnology Co., Ltd. (Shandong, China). Table 1 provides the biochemical composition of all the species which were provided by the supplier. The sample was firstly dried in a vacuum oven at $105^{\circ} \mathrm{C}$ for $24 \mathrm{~h}$ to a constant weight and then stored in a sealed plastic container for further use in the experiment. Sodium carbonate $\left(\mathrm{Na}_{2} \mathrm{CO}_{3}\right)$ was purchased from a chemical supplier (Sinopharm Chemical Reagent Co. Ltd) and was used as received. The chemical reagents that were used throughout the whole experiments were commercially available, analytical grade, and as well used as received. 
Osman Hifni et al., Saudi J Eng Technol, Dec. 2019; 4(12): 502-513

Table-1: Analysis of chemical composition and elemental distribution of Spirulina, Spartina alterniflora, and soy protein

\begin{tabular}{|c|c|c|c|}
\hline & Spartina alterniflora & Spirulina & Soy protein \\
\hline \multicolumn{4}{|c|}{ Chemical composition Analysis } \\
\hline Protein/ wt.\% & - & 70.3 & 75.8 \\
\hline Carbohydrate/ wt.\% & - & 23.9 & - \\
\hline Lipid / wt.\% & - & 5.8 & 4.54 \\
\hline Cellulose / wt. $\%$ & 35.6 & - & - \\
\hline Hemicellulose/ wt.\% & 30.9 & - & - \\
\hline Lignin / wt.\% & 11.2 & - & - \\
\hline \multicolumn{4}{|c|}{ Elemental analysis } \\
\hline $\mathrm{C} / \%$ & 41.1 & 46.9 & 48.0 \\
\hline $\mathrm{H} / \%$ & 5.7 & 6.9 & 6.76 \\
\hline $\mathrm{N} / \%$ & 0.8 & 10.7 & 13.6 \\
\hline $\mathrm{O} / \%$ & 52.4 & 35.5 & 26.6 \\
\hline $\mathrm{H} / \mathrm{C}$ & 1.66 & 1.77 & 1.69 \\
\hline $\mathrm{O} / \mathrm{C}$ & 0.96 & 0.57 & 0.42 \\
\hline $\mathrm{N} / \mathrm{C}$ & 0.02 & 0.2 & 0.24 \\
\hline Empirical formula & $\mathrm{CH}_{1.66} \mathrm{O}_{0.96} \mathrm{~N}_{0.02}$ & $\mathrm{CH}_{1.77} \mathrm{O}_{0.57} \mathrm{~N}_{0.2}$ & $\mathrm{C}_{13} \mathrm{H}_{10} \mathrm{~N}_{2}$ \\
\hline $\mathrm{HHV} /(\mathrm{MJ} / \mathrm{kg})$ & 17.8 & 18.51 & 21.2 \\
\hline Biomass types & $\begin{array}{c}\text { Lignocellulosic } \\
\text { Biomass }\end{array}$ & $\begin{array}{l}\text { Low-lipid } \\
\text { microalgae }\end{array}$ & - \\
\hline
\end{tabular}

\section{Experimental gadgets and setup}

Liquefaction experiments were performed in a relatively high-pressure unit, as shown in Fig. 1. The experimental unit consisted of an autoclave batch reactor of $50 \mathrm{ml}$ internal volume made of $316 \mathrm{~L}$ stainless steel with maximum operating conditions of $40 \mathrm{MPa}$ and $400{ }^{\circ} \mathrm{C}$. The system equipped with an electrical heating unit and some other ancillaries such as heating controller, rotary evaporator, inlet or outlet valve and cooling coil. The temperature inside the reactor was continuously monitored using a K-type thermocouple attached to the end of the reactor. The pressure in the reactor was measured using a pressure gauge attached to the reactor. The rotary evaporator was used to recover the spent reagents in the extraction process.

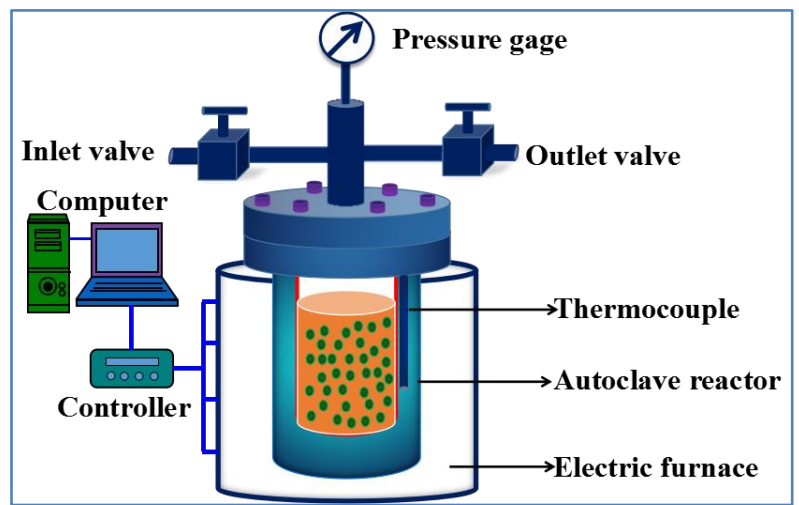

Fig-1: Schematic diagram of the experimental setup for direct liquefaction

\section{Experimental procedures}

The reactor was loaded with approximately $4 \mathrm{~g}$ of feedstock (on a dry weight basis), and $40 \mathrm{ml}$ EWCS (ethanol-water co-solvent) with different ethanol content were firstly added to the reactor. Concerning catalytic DL, the reactor was additionally loaded with a $\mathrm{Na}_{2} \mathrm{CO}_{3}$ catalyst (5 wt.\% of the dry solid for all samples). From here on, the DL process using $\mathrm{Na}_{2} \mathrm{CO}_{3}$ is termed as catalytic DL. Then, six evenly distributed bolts securely tightened to seal the reactor. The reactor was then heated to the desired temperature at the heating rate of $10 \square \mathrm{min}^{-1}$. After holding the reactor for a given reaction time at the desired temperature, the reactor was cooled down to room temperature using an electric fan. All the experiments were run three times to minimise the experimental errors for the liquefaction yields and conversion rate, and the results were displayed as the mean value.

\section{Product separation}

After the DL process, the feedstock was converted into various products including gas, liquid and solid fractions. The gas was released directly into a chemical fume hood, and then the assembly valves were opened to open the reactor and obtain the product fractions. Then a series of filtration and extraction procedures were applied to separate the products. The process to divide different product fractions is illustrated in Fig 2.

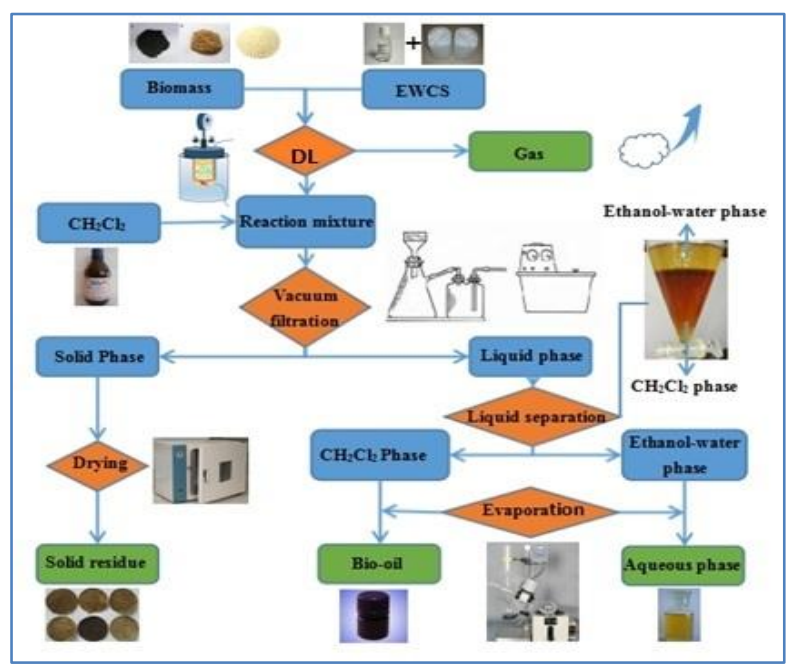

Fig-2: Procedure for separation of DL products 
The product mixture was transferred into a flask, then the reactor was rinsed with dichloromethane $\left(\mathrm{CH}_{2} \mathrm{Cl}_{2}\right)$, and the flushing liquid was added to the product mixture. After that, the mixture was vacuum filtered. Vacuum filtration was carried out using a filter paper (particle retention size of $2.5 \mu \mathrm{m}$ ) to recover the solid product. Afterwards, the filter containing the solid residue was dried to constant weight using an oven at a temperature of $105{ }^{\circ} \mathrm{C}$ for 8 hours, and then it was weighed in a sensitive electronic scale. The remaining liquid fraction, which is an organic phase consisting of the bio-oil phase, ethanol and dichloromethane were separated into ethanol-water phase and $\mathrm{CH}_{2} \mathrm{Cl}_{2}$ phase with a separating funnel. Then ethanol and dichloromethane were removed using a rotary evaporator that was operated at $40{ }^{\circ} \mathrm{C}$ and reduced pressure to obtain the final product termed as bio-oil.

The product yields for the experiments, including bio-oil, solid residue, and other (gas + aqueous phase) yields. The feedstock conversion rates were calculated on a dry basis. The yields and conversion rates were obtained using the follows formulas:

Bio-oil yield $(\%)=$ (mass of bio-oil) $/$ (mass of Spirulina) $\times 100 \%$

Solid residue yield $(\%)=($ mass of solid residue $) /($ mass of Spirulina) $\times 100 \%$

Conversion rate $(\%)=(100 \%)-$ solid residue yield (3)

Others yield $(\%)=(100 \%)$ - bio-oil yield- solid residue yield (4)

\section{Product analysis}

Chemical composition of bio-oil was tested by GC-MS (Agilent 7890A-5975C, USA) with a quadruple detector and a DB-1MS capillary column $(30 \mathrm{~mm} \times$ $0.25 \mathrm{~mm}$ inner diameter $\times 0.25 \mu \mathrm{m}$ thickness $)$. Helium (UHP) (99.999\%) was used as the carrier gas with a constant flow of $1 \mathrm{~mL} / \mathrm{min}$. The initial temperature of the oven temperature program was set at $40{ }^{\circ} \mathrm{C}$ and continued for $4 \mathrm{~min}$, rising by $5{ }^{\circ} \mathrm{C} / \mathrm{min}$ to $250{ }^{\circ} \mathrm{C}$, which held for $10 \mathrm{~min}$. The injector temperature was $250{ }^{\circ} \mathrm{C}$. The volume of injected sample $(10 \%$ of dilute bio-oil) was one $\mu \mathrm{L}$. Electron ionisation (EI) was used in the MS and standard mass spectra with $70 \mathrm{eV}$. Scan mass range of mass spectrometer was from 30 to 500 $\mathrm{m} / \mathrm{z}$ lasting for $1 \mathrm{~s}$. Compounds were identified using the National Institute of Standards and Technology mass spectral library.

\section{RESULT AND DISCUSSION \\ Effect of temperature on liquefaction}

Figure 3-5 illustrate the influence of temperature on the DL process of spirulina, soy protein and Spartina alterniflora, respectively within a range of $260{ }^{\circ} \mathrm{C}$ to $360{ }^{\circ} \mathrm{C}$, at a reaction time of $50 \mathrm{~min}$, ethanol content of $50 \mathrm{vol} \%$ and $\mathrm{S} / \mathrm{M}$ ratio (solvent to raw materials ratio) of $40 / 4 \mathrm{ml} / \mathrm{g}$. All these yields were calculated on a dry basis. As we can see in Fig. 3 for the DL process of spirulina, the maximum bio-oil yield was obtained at $320{ }^{\circ} \mathrm{C}$ with a value of $47.7 \%$ and the lowest yield at $260{ }^{\circ} \mathrm{C}$. The bio-oil yield was increased with increasing temperature, which could be due to increased hydrolysis or decomposition/depolymerisation reactions of the biomass into smaller bio-oil compounds. At higher temperatures, the activation energy required for bond cessation is easily overcome, resulting in extensive biomass depolymerisation and higher bio-oil yields [46]. After peaking at $320{ }^{\circ} \mathrm{C}$, the bio-oil yield decreased gradually co-exists with an increase in other product yields.

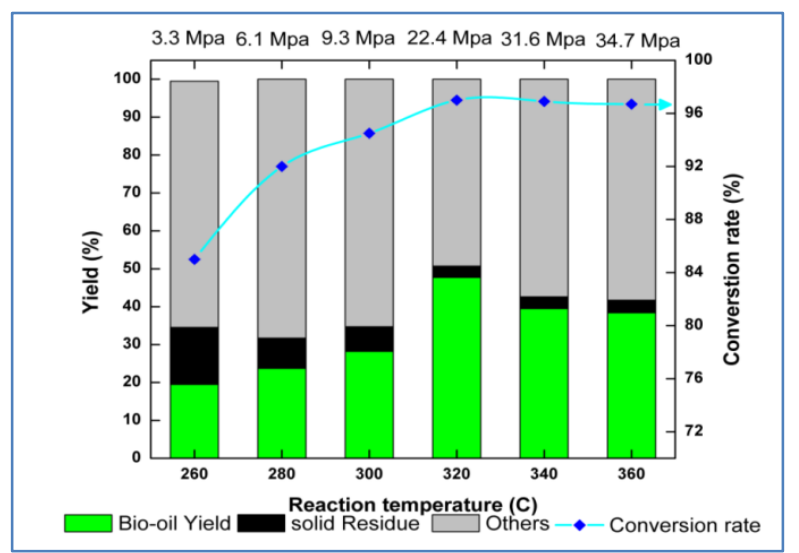

Fig-3: The product yields and conversion rate from the DL of Spirulina under different temperatures

A significant decrease in the solid residue was observed from $260{ }^{\circ} \mathrm{C}$ to $360{ }^{\circ} \mathrm{C}$, which is most likely caused by the severity of the primary decomposition of raw material at a relatively higher temperature. Most of the solid fractions were converted to either bio-oil, water-soluble or gaseous product when further increasing the temperature. Nevertheless, once the reaction temperature was high enough, the second cracking of the bio-oil could take place, causing the formation of gas and reduction of bio-oil.

It should be noted that when liquefaction took place at a low temperature $\left(260{ }^{\circ} \mathrm{C}\right)$, the yield of bio-oil was relatively low while the yield of solid residue was high, this might be mainly caused by the insufficient conversion of the raw material. The main components (lipid, protein, and carbohydrate) of the microalgae could not be wholly depolymerised and hydrolysed in that condition. In general, at a higher temperature, macromolecular are easily broken into small molecule compounds through a series of reactions such as dehydration, decarboxylation, and dihydroxylation [47]. But, new organic compounds with low molecular weight, such as bio-oil, gaseous and aqueous phases, might be further converted to ash by polymerisation, condensation, and cyclisation when raising the temperature. As a result, the bio-oil yield would not be significantly enhanced with the increase of temperature to some extent. 
As shown in Fig.4, The bio-oil yield of soy protein samples reached its maximum at $360{ }^{\circ} \mathrm{C}$ with a value of $35.4 \%$ and bottomed down at $260{ }^{\circ} \mathrm{C}$ to 21.9 $\%$. These results indicate the rising bio-oil yield with the increasing temperature, which can be altered to reaching and overlapping the required bond breaking energy. Meanwhile, solids residue had a counter-trend in which it decreased noticeably between $260{ }^{\circ} \mathrm{C}$ and $360{ }^{\circ} \mathrm{C}$. Owing to that to the primary decomposition of raw material at relatively higher temperatures in which protein initially decomposes to form primarily watersoluble N-containing compounds. As can be seen from Fig. 4, these water-soluble compounds could dimerise and oligomerize in secondary reactions to form more significant compounds that would be extracted as biooil. It's worth mention that our findings correspond with the results of Luo et al. [48].

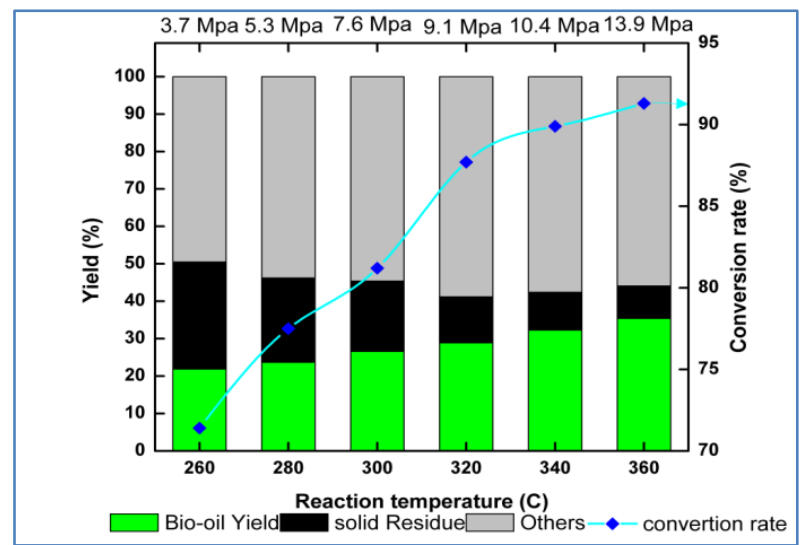

Fig-4: The product yields and conversion rate from the DL of soy protein under different temperatures

As for Spartina alterniflora, it can be seen in Fig. 5 that the yield of bio-oil and the conversion rate were namely increased with increasing temperature, peaking up at $340{ }^{\circ} \mathrm{C}$ with a bio-oil yield of $40.27 \%$ and a solid residue of $12 \%$. The conversion rate followed the same trend as bio-oil, with a peak of $88 \%$ at the same temperature. Furthermore, the final pressure kept on increasing throughout the experiment, starting with $3.3 \mathrm{MPa}$ at $260{ }^{\circ} \mathrm{C}$ up to $13.3 \mathrm{MPa}$ at $360{ }^{\circ} \mathrm{C}$. It worth pointing out that our findings are consistent with the results of Ji et al. [45]. It's also noticeable that the biooil yield of Spartina alterniflora was much lower than that of Spirulina (about 5.9\%) which can be due to the differences in the component distribution, for the lignocellulosic biomass pond break down needs higher temperatures than that from Spartina alterniflora. Finally, an overall view of all the samples (Soy protein, Spirulina, Spartina alterniflora) was conducted as can be seen in Fig. 6, where the $3 \mathrm{D}$ waterfall shows the bodies of the bio-oil yields for all the samples. It displayed the same flow in the early stages of the heating process then started to differ between 320 to $360{ }^{\circ} \mathrm{C}$.

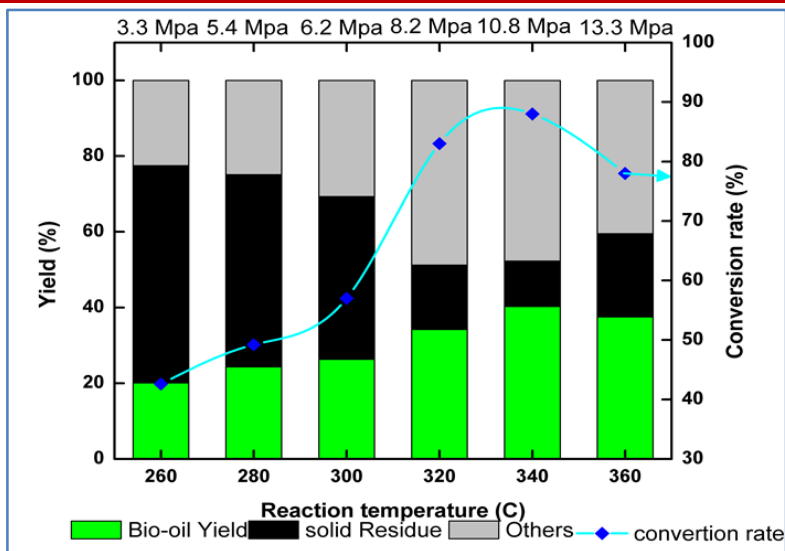

Fig-5: The product yields and conversion rate from the DL of Spartina alterniflora under different temperatures

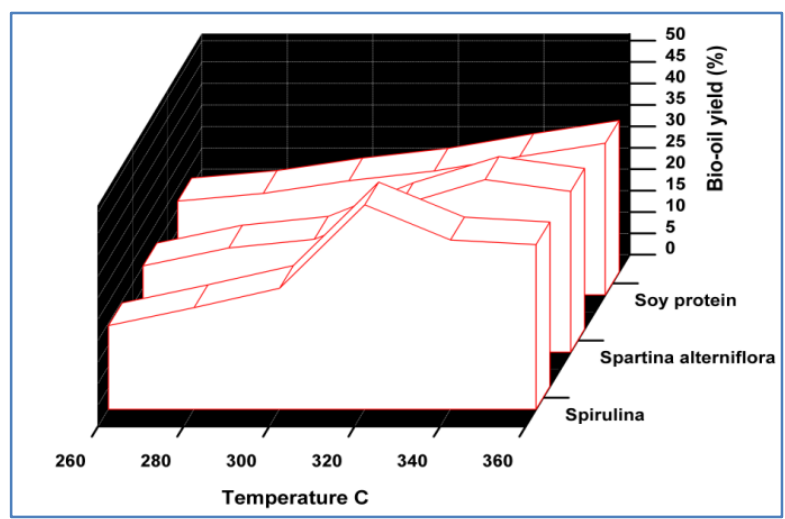

Fig-6: Three-dimensional waterfall overview of the temperature effect on the bio-oil yield

\section{Effect of EWCS on liquefaction}

In order to investigate the impact of ethanol to water ratio on product yields, the experiments in cosolvent with different ethanol content (0 to 100 vol.\%) were carried out at a reaction temperature of (320 ${ }^{\circ} \mathrm{C}, 340{ }^{\circ} \mathrm{C}, 360{ }^{\circ} \mathrm{C}$ ) accordingly, reaction time of 50 $\mathrm{min}$, and $\mathrm{S} / \mathrm{M}$ ratio of $40 / 4 \mathrm{ml} / \mathrm{g}$, as illustrated in Fig. 79. The presence of ethanol in water showed a nonnegligible effect on the DL process for Spirulina as shown in Fig. 7. It can be seen that there was a rising trend in the bio-oil yield with the increase in the ethanol content up to $50 \mathrm{vol} \%$, and then an opposite trend was observed. On the other hand, with the increasing of the ethanol content, the amount of solid residue decreased rapidly, reaching its lowest value with ethanol concertation of 50 vol. $\%$ followed by a sharp increase in the solid residue yield when increasing to $100 \mathrm{vol} \%$. The yields of other products demonstrated a similar trend to that of the solid residue with increasing of ethanol content. Moreover, these results crossbands with a recent disclosure by Zhang et al. [49], in which they reported an increase of the bio-oil yield by $11 \%$ through using ethanol as a co-solvent. 
Osman Hifni et al., Saudi J Eng Technol, Dec. 2019; 4(12): 502-513

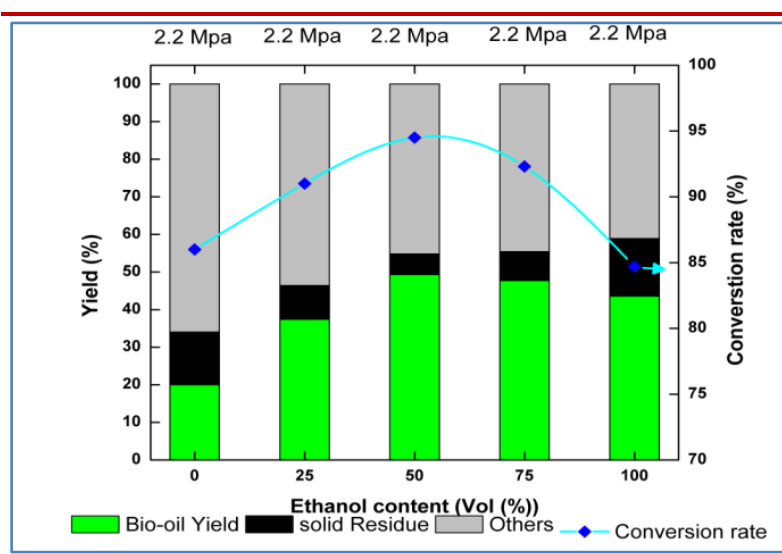

Fig-7: Product yields and conversion rate from the DL of Spirulina under different ethanol contents

Several reasons may cause the influence of ethanol on the liquefaction process. Starting with the acidity, where the acidity of water is stronger than that of ethanol, which enhances the free radical reactions and ion reactions [50]. Moreover, ethanol has a lower dielectric constant than that of water, which would improve the decomposition for high-molecular-weight components, as well as working as a free radical for stable hydrogen supply. These effects can finally increase the bio-oil yield and reduce re-polymerisation reactions [51]. The use of excessive ethanol could result in a reduction of free radicals while using the excess water could result in a rising trend in self-condensation reactions. Therefore, the optimum condition in which the highest bio-oil yield coupled with the lowest solid residue yield could be achieved using co-solvent with the appropriate ratios as the reaction medium. On the other hand, Fig. 8 shows the effect of the EWCS system on the bio-oil production from soy protein. It can be seen that the bio-oil yield increased with increasing of ethanol content to $75 \mathrm{vol} \%$, where the bio-oil yield peaked up with about $44.7 \%$, followed by a decreasing trend after that point.

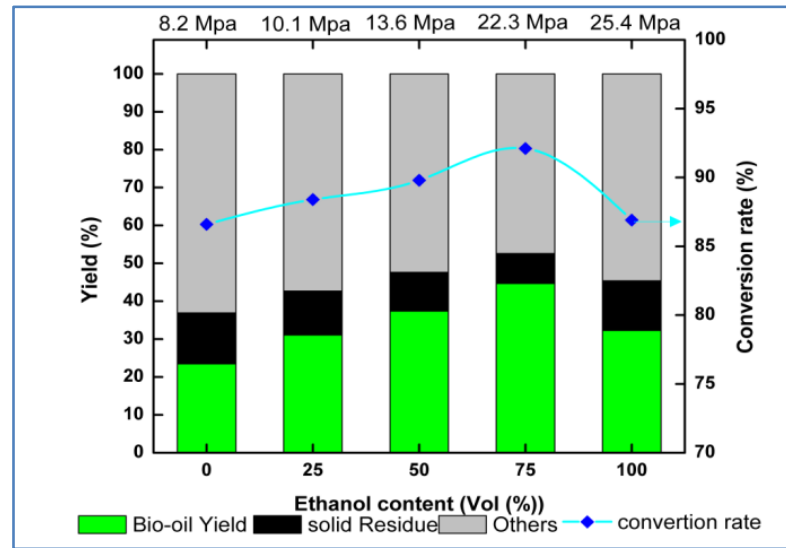

Fig-8: The impact of EWCS on product yields and conversion rate from the DL of soy protein

As for the solid residue, a reciprocal tenor was noticed in which the increase in ethanol content resulted in a sally decrease in the solid residue yield but a sharp increase when the ethanol content was increased to higher than 75 vol.\%. This can be explained by the repolymerisation of partial bio-oil caused by the reduction of free-radical reactions due to the excess ethanol. Also, from the Fig. 8, it can be seen that the EWCS system had a higher biomass conversion rate than both the pure water and ethanol system as well as bio-oil yield. Following the previously mentioned reasons $[50,51]$, it indicates the superiority of the EWCS system in reducing the solid residue and enhancing the bio-oil yield at the same time. This finding also converges with the reports of Sun et al. [52], in which they stated that along with the concentration of ethanol increases, the protein was denatured violently as high-molecularweight protein aggregation produced by natural soybean turns into low-molecular-weight protein aggregation which can be dissolved by ethyl alcohol to form enormous amount of dissolution. That could be the reason that extractive protein molecular weight increases with increasing the concentration yield higher bio-oil content.

As for S. alterniflora, the effect of ethanol on product yields was similar to that of the Spirulina as can be seen from Fig. 9. When the ethanol content was less than $75 \%$, the bio-oil yield increased noticeably, and the residue yield decreased accordingly peeking up at $75 \%$ where the yield of bio-oil and residue reached the maximum and the minimum, respectively. It can also be altered to the acidity and dielectric constant differences between water and ethanol, as previously discussed [50, 51]. These effects are probably caused by the variations in the contents of the formatted component for each sample of algae.

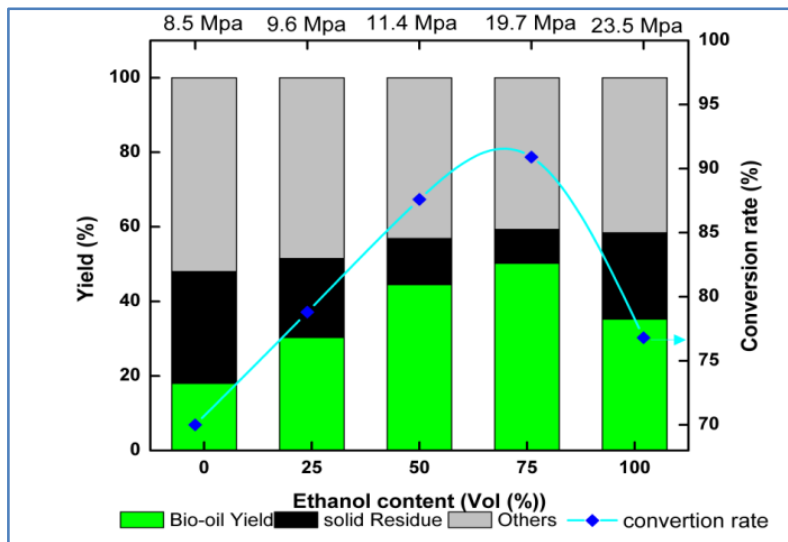

Fig-9: The product yields and conversion rate from the DL of Spartina alterniflora under different ethanol contents

Finally an overall view of all the samples (Soy protein, Spirulina, Spartina alterniflora) was conducted as can be seen in Fig.10, where the 3D waterfall shows the bodies of the bio-oil yields for all the samples under the effect of ethanol addition, peaking up in the range of 50 to 75 vol. \% ethanol. 
Osman Hifni et al., Saudi J Eng Technol, Dec. 2019; 4(12): 502-513

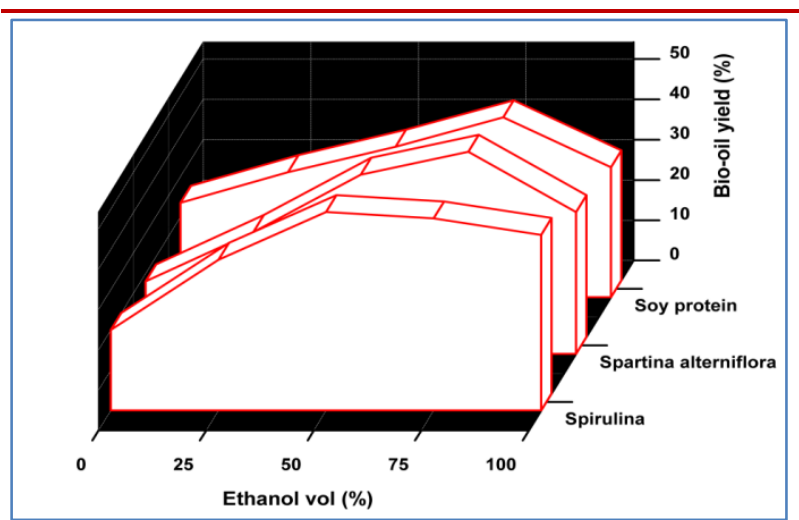

Fig-10: Three-dimensional waterfall overview of the ethanol content effect on the bio-oil yield

\section{Effect of reaction time on liquefaction}

The reaction time was defined as the period in which the temperature maintained for liquefaction, disregarding the transient heating and cooling periods. Reaction time is normally limited to $60 \mathrm{~min}$, but sometimes it can be extended up to $120 \mathrm{~min}$ [53]. The study of Jena et al. [54] showed that the bio-oil yield at $350{ }^{\circ} \mathrm{C}$ increased while increasing the reaction time up to $60 \mathrm{~min}$, but showed an opposite trend when the time was furtherer increased. Therefore, in this study DL at different reaction time, between 20 to $80 \mathrm{~min}$, was performed under a reaction temperature of $\left(320^{\circ} \mathrm{C}\right.$, $340^{\circ} \mathrm{C}$ and $360{ }^{\circ} \mathrm{C}$ ) ethanol content of $50 \mathrm{vol} . \%$ and $\mathrm{S} / \mathrm{M}$ ratio of $40 / 4 \mathrm{~mL} / \mathrm{g}$.

Figure 11-13 represent the outcomes of the DL experiments. It can be seen from Fig. 11 that the reaction time had a substantial effect on the bio-oil and solid residue yields of Spirulina. The bio-oil yield rapidly rose from 23.2 to $49.4 \%$ when increasing the reaction time from 20 to $40 \mathrm{~min}$, following that point, there was a noticeable graded decrease to $35.2 \%$ at 80 $\min$. The reduction in the bio-oil yield at the longer reaction time is probably attributed to the conversion of light hydrocarbon compounds in the bio-oil into aqueous and gaseous phase's products. That is why the number of other products rose from $42.6 \%$ at $40 \mathrm{~min}$ to $57.8 \%$ at $80 \mathrm{~min}$. On the contrary, the solid residue yield reached its minimum of $5.5 \%$ at $60 \mathrm{~min}$ which is agreed with the findings of Jena et al. [54] in which they stated that the reduction of solid residue yield reached its peak at $60 \mathrm{~min}$ followed with little change in the yield between 60 to $120 \mathrm{~min}$. It can be seen from the figure that there was a slight increase in the solid residue yield as the reaction time increased from 60 to $80 \mathrm{~min}$, this can be due to the presence of ethanol, and in which ethanol is working as a free radical for stable hydrogen supply and reduce the re-polymerization reactions [51].

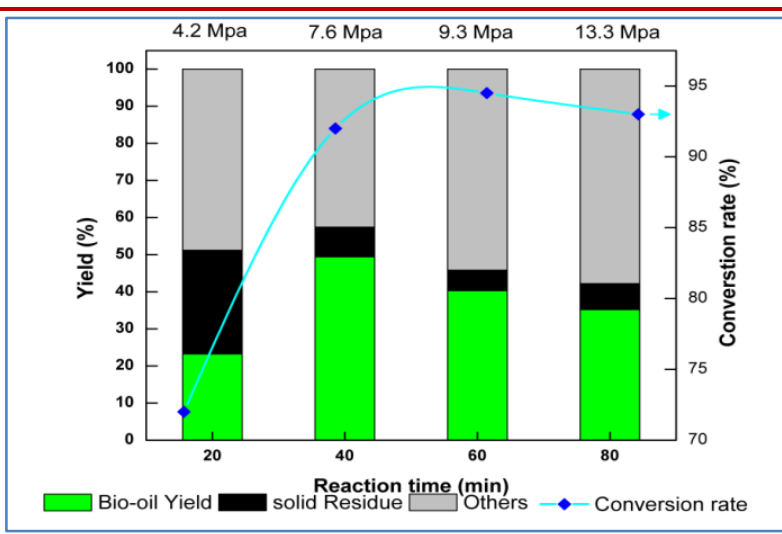

Fig-11: The product yields and conversion rate from the DL of Spirulina under different reaction times

The effect of reaction time on the liquefaction of soy protein can be seen from Fig. 12, where the biooil yield increased with the increasing reaction time peaking up at $60 \mathrm{~min}$ with $37.4 \%$, and then it decreased to $32.6 \%$ at $80 \mathrm{~min}$. Longer reaction time could promote the protein conversion, which was decomposed to form primarily water-soluble N-containing compounds.

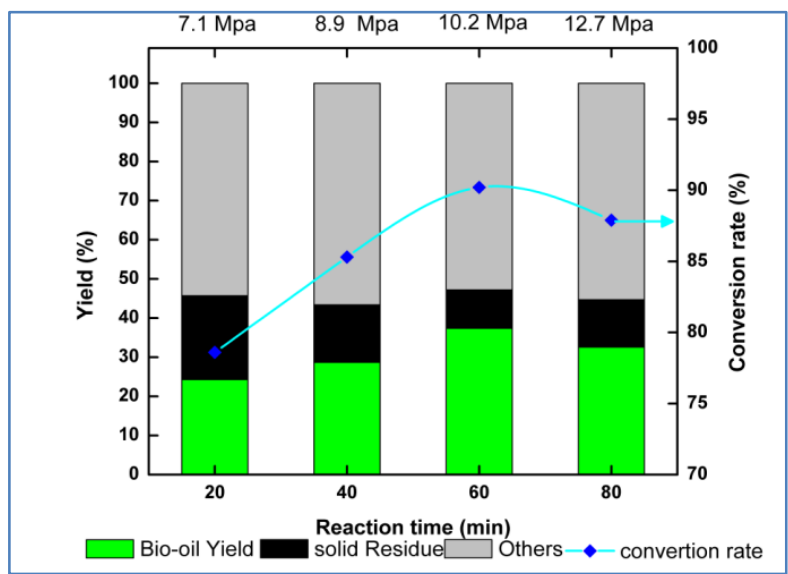

Fig-12: The product yields and conversion rate from the DL of Soy protein under different reaction times

These water-soluble compounds could dimerize and oligomerize in secondary reactions to form more significant compounds that would be extracted as bio-oil. Thus, both the bio-oil yield and its $\mathrm{N}$-content would increase with time. As time increased further, however, the bio-oil compounds could eliminate N- (and O-) containing functional groups via reactions such as deamination and decarboxylation which can be justified by the decrease in bio-oil yield after $60 \mathrm{~min}$. As well as the relatively severe conditions of this experiments will allow the small organic materials produced by decarboxylation and deamination of the protein to re-polymerise by Fischer-Tropsch type reactions to form longer chain hydrocarbons and aromatic ring-type structures such as phenols and nitrogen heterocycles (indole or pyrroles) which were the compounds of bio-oil from liquefaction of protein. 
Figure 13 represents the effect of reaction time on the DL of Spartina alterniflora. It can be seen from the figure that the reaction time has an un-neglectable impact on the bio-oil and solid residue yields. The biooil yield rapidly rose from 25.3 to $49.2 \%$ when increasing the reaction time from 20 to $60 \mathrm{~min}$, following that point, there was a noticeable graded decrease to $43.9 \%$ at $80 \mathrm{~min}$. The reduction in the biooil yield at higher reaction time was probably attributed to the conversion of lighter hydrocarbon compounds in the bio-oil into aqueous and gaseous phase's products. On the contrary, the solid residue yield reached its minimum of $10.2 \%$ at $60 \mathrm{~min}$ as well as a slight increase with the reaction time increased from 60 to 80 min which might be due to the presence of ethanol as previously mentioned [51].

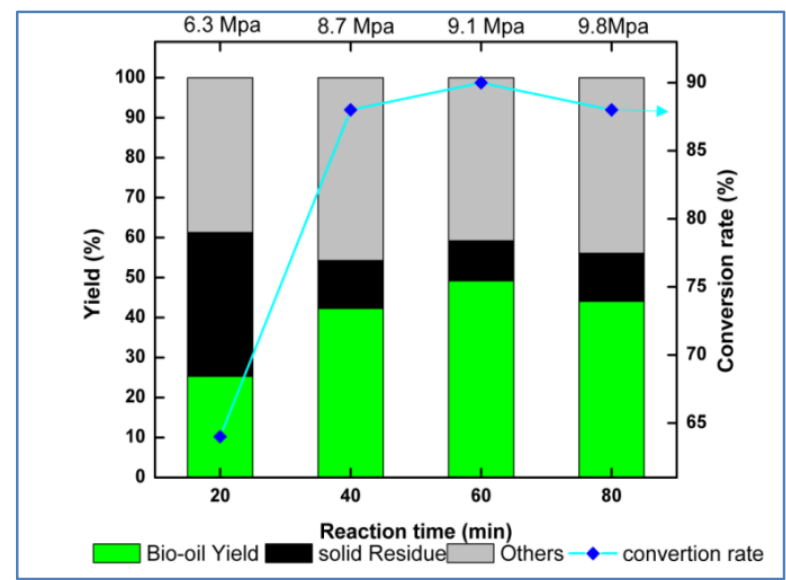

Fig-13: The effect of reaction time on product yields and conversion rate from the DL of Spartina alterniflora

Finally, an overall view of all samples (Soy protein, Spirulina, Spartina alterniflora) was conducted as can be seen in Fig 14 where the 3D waterfall shows the bodies of the bio-oil yields for all the samples under the effect of residence time, in which the optimum time registered, were in the range of 40 to $60 \mathrm{~min}$.

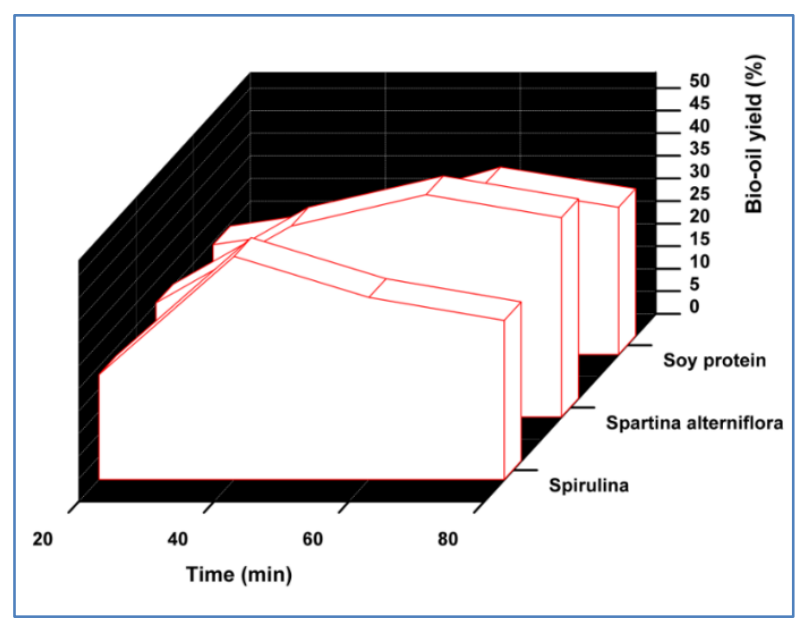

Fig-14: Three-dimensional waterfall overview of the residence time effect on the bio-oil yield

\section{Effect of $\mathrm{Na}_{2} \mathrm{CO}_{3}$ on liquefaction}

The effect of an alkaline catalyst on liquefaction process at a reaction temperature of 320 ${ }^{\circ} \mathrm{C}, 340{ }^{\circ} \mathrm{C}$, and $360{ }^{\circ} \mathrm{C}$ accordingly, the reaction time of $40,60 \mathrm{~min}$, and $\mathrm{S} / \mathrm{M}$ ratio of $40 / 4 \mathrm{~mL} / \mathrm{g}$, was discussed. The bio-oil yield for Spirulina was enhanced noticeably from 49.4 wt.\% without the use of the catalyst to 53.7 wt.\% with the addition of $\mathrm{Na}_{2} \mathrm{CO}_{3}$. This enhancement is probably due to the higher amount of carbohydrates presented in the microalgae Spirulina, in which it was converted to bio-oil with higher efficiency when $\mathrm{Na}_{2} \mathrm{CO}_{3}$ was used [55]. On the other hand, $\mathrm{Na}_{2} \mathrm{CO}_{3}$ also reacts with water to form its hydroxide and bicarbonate, which has been identified as an intermediate and assumed to be the secondary promoter in the liquefaction process [56].

Thus, it was obvious that the presence of $\mathrm{Na}_{2} \mathrm{CO}_{3}$ could increase the rate of the decomposition reaction of microalgae Spirulina in a pressurized EWCS System. With the presence of $\mathrm{CO}$ generated from organics constituents in the Spirulina, $\mathrm{Na}_{2} \mathrm{CO}_{3}$ would react with it to form $\mathrm{CH} 3-\mathrm{CO}-\mathrm{Na}$ (sodium formate), which promotes the formation of $\mathrm{HCOO}-$ and $\mathrm{OH}-$ ions. Both ions would enhance the decomposition of hydrocarbon macromolecules into various short-chain organic compounds. The compounds would undergo condensation, cyclisation, and polymerisation, thus improving the formation of bio-oil [57]. As for the solid residue, it encountered a decreasing trend which might be caused by $\mathrm{Na}_{2} \mathrm{CO}_{3}$, which enhances more carbohydrates to be converted to bio-oil and restrain the formation of char.

On the other hand, $\mathrm{Na}_{2} \mathrm{CO}_{3}$ catalyst inhabited the conversion of soy protein. The bio-oil yield decreased to about $31.6 \%$, as well as a noticeable decrease in the solid residue amount. It can be understood the following mechanism of oil formation from proteins. The $\mathrm{C}-\mathrm{N}$ peptide bond between the carboxyl and amino groups is obtained from the amino acids hydrolysing, and it will become blocking the conversion of the protein. The amino acids formed by this process is subsequently degraded by decarboxylation and deamination [58], resulting in large amounts of the carbohydrates break down to polar water-soluble organics such as formic acid, acetic acid, lactic acid, acrylic acid, 2-furaldehyde, and 1,2,4benzenetriol. Most of these compounds are polar organics that are apt to dissolve in the water phase with little contribution to the bio-oil yield. Meanwhile, the formation of the non-polar hydrocarbon type structures would also lead to an overall reduction in bio-oil yield [59].

The alkaline catalyst displayed a beneficial influence on oil formation from carbohydrates which was not observed for the proteins indicating that $\mathrm{Na}_{2} \mathrm{CO}_{3}$ is selectively promoting decarboxylation of carbohydrates, leading to a lower fraction of product in 
the other phases than for proteins. It can be concluded that soy protein was converted to bio-oil most efficiently without the use of the catalyst. As for S.alterniflora, the use of the alkaline catalyst allows the maximum production of bio-oil $(42.21 \%)$ and the minimum creation of solid residue $(13.00 \%)$. Thus, the maximum bio-oil yield was slightly higher than that of DL. The effect of the catalyst on the liquefaction of S.alterniflora was studied, which showed a significant influence on bio-oil yield. The bio-oil yield obtained from catalytic liquefaction was higher compared with DL. It can be inferred that S.alterniflora is split into much smaller molecules under the action of $\mathrm{Na}_{2} \mathrm{CO}_{3}$. Alkali metals and alkaline earth metals salts catalysts are widely used in the thermochemical conversion of lignocellulosic biomass to promote the yield of gaseous products.

The lower solid residue from catalytic liquefaction was observed than that from DL, in other words, the action of $\mathrm{Na}_{2} \mathrm{CO}_{3}$ resulted in the increase of conversion rate during the liquefaction where the catalyst had a promotion function of hydrolysis and the dominated main components of S.alterniflora. So, $\mathrm{Na}_{2} \mathrm{CO}_{3}$ played an essential role in relieving acid value of co-solvent reaction medium to maintain a stable free radical reaction and thus causing the improvement of the bio-oil production.

\section{Characterization of bio-oil \\ FT-IR analysis of bio-oil}

The FT-IR analysis of the bio-oil provides indepth details about the functional group's information. Figure 15 shows the FT-IR spectrum of the bio-oil for all the three samples ((A) Spirulina, (B) Spartina alterniflora, (C) Soy protein) produced at optimum conditions. As can be seen from Fig. 15 that the spectra of bio-oils from the algae displayed similar behavior and profiles, which indicates the presence of similar chemical structures within the bio-oil. A broad and deep absorption peak was present at the band of $\sim 3290 \mathrm{~cm}^{-1}$ (1) where $\mathrm{O}-\mathrm{H}$ stretching of hydroxyl compounds appears. The bands between $3000 \sim 2800 \mathrm{~cm}^{-1}$ (2) likely correspond to $\mathrm{C}-\mathrm{H}$ stretches in methylene groups and long-chain aliphatic hydrocarbons. The $\mathrm{C}=\mathrm{O}$ characteristic absorption region at $\sim 1700 \mathrm{~cm}^{-1}$ (3) indicates the presence of acid, ketone, aldehydes and esters in bio-oil [60].

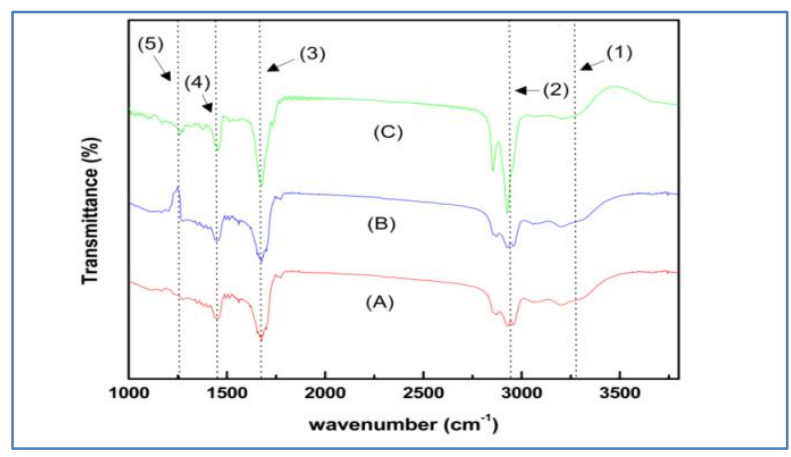

Fig-15: FT-IR analysis of bio-oil from Spirulina (A), Spartina alterniflora (B), and Soy protein $(\mathrm{C})$ at optimum conditions

Table-2: FT-IR results of given groups of bio-oil samples

\begin{tabular}{|l|l|l|l|}
\hline Number & Wavenumber $\left[\mathbf{c m}^{-1}\right]$ & Band assignment & Functional groups \\
\hline 1 & $3350 \sim 3290$ & $\mathrm{O}-\mathrm{H}$ & water, phenols, fatty acid amides \\
\hline 2 & $3000 \sim 2800$ & $\mathrm{C}-\mathrm{H}$ & $-\mathrm{CH}_{2}$ and $-\mathrm{CH}_{3}$ methyl \& methylene groups \\
\hline 3 & $1750 \sim 1650$ & $\mathrm{C}=\mathrm{O}$ & carboxylic acids, ketones and aldehydes \\
4 & $1450 \sim 1350$ & $\mathrm{C}-\mathrm{H}$ & fats and esters \\
5 & $1300 \sim 1200$ & $\mathrm{C}-\mathrm{O}$ & acids, alcohols or esters \\
\hline
\end{tabular}

As for the absorption at $\sim 1400 \mathrm{~cm}^{-1}(4)$, it could be related to the appearance of the bending bands for methylene groups. It can be seen that the intensity within the (C) spectrum was much stronger, which is probably due to the higher hydrogen and carbon content in this sample. Finally, the region at $\sim 1250 \mathrm{~cm}^{-1}$ (5) that is only present in the (B) spectrum represents the presence of phenols and esters with a much higher amount than the other samples.

\section{GC-MS analysis of bio-oil}

The GC-MS analysis was applied to the bio-oil obtained from the optimum conditions to further determine the main chemical compounds of the bio-oils produced from DL of Soy protein, Spirulina, and Spartina alterniflora. Table 3 displays the tentative identities of the most significant peaks in the chromatograms, as well as the chemical names for major compounds. Accordingly, the most significant peaks in the chromatograms of the bio-oil are shown in Table 3, which are more than $1.2 \%$ of the total peak area.

As can be seen from the table that the main components of the Spirulina bio-oil can be classified into several groups such as esters, ketones, amides, acids, and nitrogen-containing heterocycles. Also, the high protein content in the Spirulina sample resulted in a higher proportion of protein-derived pyrroles and indoles as well as some hepta and hexadecane. Moreover, most of these compounds contain oxygen fractions driven from the decomposition of proteins and carbohydrates, leading to the presence of high oxygen content within the bio-oil. The high oxygen content would affect the thermal stability of the bio-oil, so further refinement and upgrading are required, such as 
Osman Hifni et al., Saudi J Eng Technol, Dec. 2019; 4(12): 502-513

hydrogenation and de-nitrification to extract highquality liquid fuel that is more stable and suitable for downstream applications. The main compounds of the bio-oil of Spartina alterniflora were acids, phenols, esters, and furan, but the phenols and indoles were fewer. The most abundant compounds for Soy protein samples were esters and methyl compounds.

It can be noted that when comparing with the bio-oil from HTL and EWCS, most of the dominant compounds in bio-oil from EWCS had a relatively lower content except for hexadecanoic acid ethyl ester. Also, some esters including 5, 8, 11, 14Eicosatetraenoic acid, ethyl ester, (all-Z)- and ethyl linoleate increased as well as in the bio-oil from EWCS. These results indicated that the addition of ethanol into the DL system can lead to esterification in which ethanol sever as substrate reacting with acidic compounds as shown in Eq. (5).

\section{$\mathrm{R}-\mathrm{COOH}+\mathrm{C}_{2} \mathrm{H}_{5} \mathrm{OH} \rightarrow \mathrm{RCOOC}_{2} \mathrm{H}_{5}+\mathrm{H}_{2} \mathrm{O}$} (5)

On the other hand, processing with $\mathrm{Na}_{2} \mathrm{CO}_{3}$ did not have a significant effect on the elemental composition of the bio-oil, while it might contribute to the high amounts of nitrogen content that were present in the bio-oil. Similar results were reported by Ross et al. [41], as mentioned earlier that the nitrogen could affect the stability and purity of the fuel and also result in catalyst deactivation through coke formation eventuated from the adsorption of the nitrogen that is mixed with hydrocarbon molecules [61]. As for the organic acids, the introducing of $\mathrm{Na}_{2} \mathrm{CO}_{3}$ obtained a bio-oil with nearly the same organic acids and a handful of other cyclic organic acids like methyl-3methylphenylester-, carbamic acid, and 1HIndole- 3propanoic acid. Also, the aromatic hydrocarbons had a lower percentage, which could be caused by the catalytic effect of $\mathrm{Na}_{2} \mathrm{CO}_{3}$ that enhances the break-down of lipids to alkanes. Also processing with $\mathrm{Na}_{2} \mathrm{CO}_{3}$ displayed the presence of the acyclic alcohol phytol, phenol derivatives, and hexadecane. Porphyridium produces large amounts of indole using $\mathrm{Na}_{2} \mathrm{CO}_{3}$ but also phenolic and phytol compounds. To sum up, the higher the protein contents of the algal feedstock, the higher the fraction of nitrogen heterocycles, pyrroles, and indoles in the bio-oil. Using sodium carbonate increased the formation of phenolic compounds and also increased the breakdown of lipids to alkanes, as mentioned previously.

Table-3: Main chemical compositions of bio-oil obtained at optimum conditions

\begin{tabular}{|l|l|c|c|}
\hline Name of compounds & Spirulina & $\begin{array}{c}\text { Ares/\% } \\
\text { Soy protein }\end{array}$ & Spartina alterniflora \\
\hline Pyrazine, methyl- & 1.60 & - & 3.45 \\
\hline Cyclopropane, (methoxymethyl)- & 1.22 & - & - \\
\hline Pyrazine, 2-ethyl-6-methyl- & 1.48 & 0.27 & 1.28 \\
\hline 1H-Pyrrole-1-ethanamine, tetrahydro-.alpha.-methyl- & 2.77 & 2.02 & - \\
\hline Piperidine, 1-pentyl- & 1.42 & 0.67 & - \\
\hline 2,5-Pyrrolidinedione, 1-methyl- & 1.99 & 2.27 & - \\
\hline Benzeneethanamine & 2.51 & - & - \\
\hline 1H-Pyrrole, 2-ethyl-3,5-dimethyl- & 1.20 & 0.32 & - \\
\hline 2,5-Pyrrolidinedione, 1-ethyl- & 1.34 & 3.06 & 1.5 \\
\hline 2,4(1H,3H)-Pyrimidinedione,6-amino-1-methyl- & 1.25 & 0.87 & 0.67 \\
\hline 1H-Pyrrole, 3-ethyl-2,4,5-trimethyl- & 1.94 & - & - \\
\hline Indole & 1.84 & 0.84 & 0.93 \\
\hline 2,5-Pyrrolidinedione, 1-butyl- & 2.77 & 2.27 & - \\
\hline 1H-Pyrrole, 3,5-dimethyl-2-phenyl- & 1.44 & - & - \\
\hline 5-Hydroxyimino-4-oxo-4,5,6,7-tetrahydrobenzofurazan & 2.48 & - & - \\
\hline 2,5-Cyclohexadien-1-one,3,5-dihydroxy-4,4-dimethyl- & 2.27 & - & - \\
\hline 1-Proline, N-allyloxycarbonyl-, pentyl ester & 2.40 & 0.73 & \\
\hline n-Hexadecanoic acid & 2.81 & - & 1.84 \\
\hline Hexadecanoic acid, ethyl ester & 15.8 & 4.47 & - \\
Linoleic acid ethyl ester & 1.94 & 2.15 & 12.37 \\
Thiophene, 2-methoxy-5-methyl- & - & 6.40 & 0.79 \\
1,4-Dioxaspiro[4.5]decane,6-methylene- & - & - \\
1-Proline, N-butoxycarbonyl-, decyl ester & - & 5.80 & - \\
1-Valine, n-propargyloxycarbonyl-, tetradecyl ester & - & 5.42 & - \\
Phenol, 4-ethyl-2-methoxy- & - & 4.65 & 2.57 \\
Phenol, 4-ethyl- & - & - & 2.44 \\
Butanoic acid, 2-methylpropyl ester & 1.42 & - & 2.94 \\
Phenol, 2-methoxy- & - & - & \\
Phenol, 2,6-dimethoxy & & - & \\
\hline
\end{tabular}


Osman Hifni et al., Saudi J Eng Technol, Dec. 2019; 4(12): 502-513

\section{CONCLUSIONS}

Within the realm of this study, the direct liquefaction of microalgae (Spirulina, Spartina alterniflora) and soy protein was performed in an autoclave batch reactor in a co-solvent system consisted of water and ethanol. Relatively higher bio-oil yields of $49.4 \%, 50.2 \%$ and $42.7 \%$ (for Spirulina, Spartina alterniflora, and Soy protein respectively) for noncatalytic runs and $53.7 \%, 50.2 \%$ and $31.6 \%$ for the catalytic runs were achieved through the optimum conditions. The GC-MS analyses displayed that there were some differences in the composition and the content of compounds among the bio-oils. The significant compounds were esters, ketones, amides, acids, and nitrogen-containing heterocycles. Apart from the positive and negative effect on the product yield, the use of $\mathrm{Na}_{2} \mathrm{CO}_{3}$ had no significant impact on the properties of the bio-oil when compared to noncatalytic HTL. The FT-IR analysis of the bio-oil obtained from the liquefaction process showed that the entire functional groups of the bio-oil were the same, indicating the chemical structure was similar, and mainly contained functional groups such as $\mathrm{O}-\mathrm{H}, \mathrm{C}-\mathrm{H}$ and $\mathrm{C}=\mathrm{O}$. The research on the direct liquefaction of low-lipid microalgae in sub/supercritical alcohol-water co-solvent is still in the preliminary exploratory research stage, although it has also made many meaningful outcomes. But there are still many aspects of research to be further deepened.

\section{ACKNOWLEDGEMENTS}

This research was supported by the National Natural Science Foundation of China (No. 51776088), the Natural Science Foundation of Higher Education Institutions of Jiangsu Province (18KJB470004) the Open Fund of Key Laboratory of Low-grade Energy Utilization Technologies and Systems (Chongqing University), Ministry of Education of China (Project No. LLEUTS-201703) and the Project Funded by the Priority Academic Program Development of Jiangsu High Education Institutions.

\section{REFERENCES}

1. Hubbert's Petroleum Production Model. (2004). An Evaluation and Implications for World Oil Production Forecasts, Alfred J. Cavallo, Natural Resources Research, 13(4).

2. The World Factbook. (2012). Central Intelligence Agency - CIA Oct 19,

3. The International Energy Agency (IEA). (2017). Key World Energy Statistics Edition

4. Duan, P., Jin, B., Xu, Y., Yang, Y., Bai, X., Wang, F. (2013). Thermo-chemical conversion of Chlorella pyrenoidosa to liquid biofuels. Bioresour Technol, 133:197-205.

5. Chen, W.H., Lin, B.J., Huang, M.Y., Chang, J.S. (2015). Thermochemical conversion of microalgal biomass into biofuels: a review. Bioresour Technol, 184:314-27.
6. Chen, W.H., Kuo, P.C. (2010). A study on torrefaction of various biomass materials and its impact on lignocellulosic structure simulated by a thermogravimetry. Energy, 35, 2580-2586.

7. National Renewable Energy Laboratory. (2004). Energy Analysis/Capabilities \& Expertise: electric infrastructure systems. An Introduction to Biomass Thermochemical Conversion Richard L., Thermochemical Conversion National Bioenergy Center DOE/NASLUGC Biomass and Solar Energy Workshops August 3-4.

8. Chornet, E., Overend, R.P. (1985). Fundamentals of thermochemical biomass conversion. Elsevier, New York, 967-1002.

9. Jena, U., Das, K.C. (2011). Comparative evaluation of thermochemical liquefaction and pyrolysis for bio-oil production from microalgae. Energy Fuels; 25:5472-82.

10. Suali, E., Sarbatly, R. (2012). Conversion of microalgae to biofuel. Renewable Sustainable Energy Rev, 16, 4316-4342.

11. Toor, S.S., Rosendahl, L., Rudolf, A. (2011). Hydrothermal liquefaction of biomass: a review of subcritical water technologies. Energ, 36:2328-42.

12. Matsui, T.O., Nishihara, A., Ueda, C., Ohtsuki, M., Ikenaga, N.O., Suzuki, T. (1997). Liquefaction of micro-algae with iron catalyst. Fuel, 76:1043-8.

13. Chen, Y., Wu, Y.L., Zhang, P.L., Hua, D.R., Yang, M.D, Li, C. (2012). Direct liquefaction of Dunaliella tertiolecta for bio-oil in sub/supercritical ethanolewater. Bioresour Technol, 124:190e8.

14. Liu, Z.G., Zhang, F.S.(2008). Effects of various solvents on the liquefaction of biomass to produce fuels and chemical feedstocks. Energy Convers Manage, 49: 3498e504.

15. Yuan, X.Z., Wang, J.Y., Zeng, G.M., Huang, H.J., Pei, X.K., Li, H.(2011). Comparative studies of thermochemical liquefaction characteristics of microalgae using different organic solvents. Energy, 36:6406e12.

16. Yamazaki, J., Minami, E., Saka, S. (2006). Liquefaction of beech wood in various supercritical alcohols. J Wood Sci, 52:527e32.

17. Huang, H.J., Yuan, X.Z., Zhu, H.N., Li, H., Liu, Y., Wang, X.L.(2013). Comparative studies of thermochemical liquefaction characteristics of microalgae, lignocellulosic biomass and sewage sludge. Energy, 56:52e60.

18. Duan, P.G., Jin, B.B., Xu, Y.P., Yang, Y., Bai, X.J., Wang, F.(2013). Thermo-chemical conversion of Chlorella pyrenoidosa to liquid biofuels. Bioresour Technol, 133:197e205

19. Mazaheri, H., Lee, K.T., Bhatia, S., Mohamed, A.R.(2010). Sub/supercritical liquefaction of oil palm fruit press fiber for the production of bio-oil: effect of solvents. Bioresour Technol, 101:7641-7.

20. Shuping, Z., Yulong, W., Mingde, Y., Kaleem, I., Chun, L., Tong, J. (2010). Production and characterization of bio-oil from hydrothermal 
liquefaction of microalgae Dunaliella tertiolecta cake, Energy, 35; 5406-5411.

21. Minowa, T., Yokoyama, S., Kishimoto, M., Okakura, T. (1995). Oil production fromalgal cells of Dunaliella tertiolecta by direct thermochemical liquefaction, Fuel. 74 (Dec 1995) 1735-1738.

22. Ross, A.B., Biller, P., Kubacki, M.L., Li, H., LeaLangton, A., Jones, J.M.(2010). Hydrothermal processing of microalgae using alkali and organic acids, Fuel 89 (Sep 2010) 2234-2243.

23. Matsui, T.O., Nishihara, A., Ueda, C., Ohtsuki, M., Ikenaga, N.O., T. (1997). Suzuki, Liquefaction of micro-algae with iron catalyst, Fuel, 76; 10431048.

24. Sawayama, S., Minowa, T., S.Y.(1999). Yokoyama, Possibility of renewable energy production and $\mathrm{CO} 2$ mitigation by thermochemical liquefaction of microalgae, Biomass Bioenergy, 17; 33-39.

25. Duan, P., Savage, P.E. (2011). Hydrothermal liquefaction of a microalga with heterogeneous catalysts, Ind. Eng. Chem. Res, 50; 52-61.

26. Becker, E. W.(2007). Micro-algae as a source of protein. Biotechnol. Adv, 25, 207-210.

27. Dote, Y., Sawayama, S., Inoue, S., Minowa, T., Yokoyama, S.(1994). Recovery of liquid fuel from hydrocarbon-rich microalgae by thermochemical liquefaction, Fuel, 73 ,1855-1857

28. Brown, T.M., Duan, P., Savage, P.E.(2010). Hydrothermal liquefaction and gasification of Nannochloropsis sp. Energy Fuels, 24, 3639-3646.

29. Hafez, I., Hassan, E.B. (2015). Rapid liquefaction of giant miscanthus feedstock in ethanol-water system for production of biofuels. Energy Convers Manage, 91:219-24.

30. Ligang, L.U.O., James, D., Sheehan, Liyi, D., \& Phillip, E. (2000). Savage, Products and Kinetics for Isothermal Hydrothermal Liquefaction of Soy Protein Concentrate, ACS Sustainable Energy \& Engineering.

31. Zhang, J., Zhang, Y. (2014). Hydrothermal liquefaction of microalgae in an ethanol-water cosolvent to produce biocrude oil, Energy Fuel, 28; 5178-5183.

32. Liu, Y., Yuan, X.Z., Huang, H.J., Wang, X.L., Wang, H., Zeng, G.M. (2013). Thermochemical liquefaction of rice husk for bio-oil production in mixed solvent (ethanol-water). Fuel Process Technol, 112:93-9.

33. Yuan, X.Z., Li, H., Zeng, G.M., Tong, J.Y., Xie, W.(2007). Sub- and supercritical liquefaction of rice straw in the presence of ethanol-water and 2propanol-water mixture. Energy, 32:2081-8.

34. Effects of Alcohol Destiny on the Waste of Soy Protein Concentrate, Sun Bingyu, Shi Yanguo, Harbin University of Commerce, Food Engineering Institute Harbin.

35. Barreiro, D.L., Prins, W., Ronsse, F., Brilman, W. (2013). Hydrothermal liquefaction (HTL) of microalgae for biofuel production: state of the art review and future prospects. Biomass Bioenergy, 53, 113-127.

36. Jena, U., Das, K.C., Kastner, J.R. (2011). Effect of operating conditions of thermochemical liquefaction on biocrude production from Spirulina platensis. Bioresour. Technol, 102, 6221-6229.

37. Yeh, T.M., Dickinson, J.G., Franck, A., Linic, S., Thompson, L.T., Savage, P.E.(2013). Hydrothermalcatalytic production of fuels and chemicals from aquatic biomass, J. Chem. Technol.Biotechnol, 88, 13-24.

38. Akhtar, J., Kuang, S.K., Amin, N.S. (2010). Liquefaction of empty palm fruit bunch (EPFB) in alkaline hot compressed water. Renew Energy, 35:1220-7.

39. Jena, U., Das, K. C., \& Kastner, J. R. (2012). Comparison of the effects of $\mathrm{Na} 2 \mathrm{CO} 3, \mathrm{Ca} 3$ (PO4) 2 , and $\mathrm{NiO}$ catalysts on the thermochemical liquefaction of microalga Spirulina platensis. Applied Energy, 98, 368-375.

40. Peterson, A.A., Vogel, F., Lachance, R.P., Froling, M., Antal Jr., M.J., Tester, J.W.(2008). Thermochemical biofuel production in hydrothermal media: a review of suband supercritical water technologies. Energy Environ. Sci, 1, 32-65.

41. Srokol, Z., Bouche, A.G., Van, Estrik, A., Strik, R.C.J., Maschmeyer, T., Peters, J.A. (2004). Hydrothermal upgrading of biomass to biofuel; studies on somemonosaccharide model compounds. Carbohydr. Res. 339, 1717-1726.

42. Yuan, X., Wang, J., Zeng, G., Huang, H., Pei. X., Li, H. (2011). Comparative studies of thermochemical liquefaction characteristics of microalgae using different organic solvents. Energy, 36(11):6406-12.

43. O'Connor, P., Pouwels, A.C. (1994). FCC Catalyst Deactivation: A Review and Directions for further Research, Catalyst Deactivation, Elsevier, Amsterdam, 129144. 